Bryant University

Bryant Digital Repository

Management Department Journal Articles

Management Faculty Publications and

Research

2006

\title{
Radio Frequency Identification Technology: Applications, Technical Challenges and Strategies
}

\author{
Suhong Li \\ Bryant University, sli@bryant.edu \\ John K. Visich \\ Bryant University, jvisich@bryant.edu \\ Basheer M. Khumawala \\ University of Houston \\ Chen Zhang \\ Bryant University, czhang@bryant.edu
}

Follow this and additional works at: https://digitalcommons.bryant.edu/manjou

Part of the Business Administration, Management, and Operations Commons, and the Management Sciences and Quantitative Methods Commons

\section{Recommended Citation}

Li, Suhong; Visich, John K.; Khumawala, Basheer M.; and Zhang, Chen, "Radio Frequency

Identification Technology: Applications, Technical Challenges and Strategies" (2006).

Management Department Journal Articles. Paper 34.

https://digitalcommons.bryant.edu/manjou/34

This Article is brought to you for free and open access by the Management Faculty Publications and Research at Bryant Digital Repository. It has been accepted for inclusion in Management Department Journal Articles by an authorized administrator of Bryant Digital Repository. For more information, please contact dcommons@bryant.edu. 


\title{
Research article
}

\section{Radio frequency identification technology: applications, technical challenges and strategies}

\author{
Suhong Li \\ Bryant University, Smithfield, Rhode Island, USA \\ Fohn K. Visich \\ Bryant University, Smithfield, Rhode Island, USA \\ Basheer M. Khumawala \\ C.T. Bauer College of Business, University of Houston, Houston, Texas, USA \\ Chen Zhang \\ Bryant University, Smithfield, Rhode Island, USA
}

\begin{abstract}
Purpose - The purpose of this paper is to discuss the technology behind RFID systems, identify the applications of RFID in various industries, and discuss the technical challenges of RFID implementation and the corresponding strategies to overcome those challenges.

Design/methodology/approach - Comprehensive literature review and integration of the findings from literature.

Findings - Technical challenges of RFID implementation include tag cost, standards, tag and reader selection, data management, systems integration and security. The corresponding solution is suggested for each challenge.

Research limitations/implications - A survey type research is needed to validate the results.

Practical implications - This research offers useful technical guidance for companies which plan to implement RFID and we expect it to provide the motivation for much future research in this area.

Originality/value - As the infancy of RFID applications, few researches have existed to address the technical issues of RFID implementation. Our research filled this gap.
\end{abstract}

Keywords Identification, Radio frequencies, Technology led strategy

Paper type Literature review

\section{Introduction}

Radio frequency identification (RFID) systems have received increased attentions from academicians and practitioners. It is a data acquisition and storage method, providing accurate, real-time data without human intervention. With its advent, various business processes are poised for a new and rapid transformation. RFID technology promises numerous benefits in supply chain management: improved speed, accuracy, efficiency and security of information sharing across the supply chain (Jones et al., 2004), reduced storage, handling and distribution expenses; increased sales through reduced stock outs; and improved cash flow through

The current issue and full text archive of this journal is available at www.emeraldinsight.com/0260-2288.htm

Sensor Review

26/3 (2006) 193-202

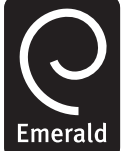

C Emerald Group Publishing Limited [ISSN 0260-2288] [DOI 10.1108/02602280610675474] increased inventory turns (Käkkäinen, 2003). RFID technology can be used to track documents such as library books and legal files (Collins, 2004a), and pharmaceutical drugs (Collins, 2004b), to track and manage hospital equipment and surgical instruments (McGee, 2004).

The major drivers behind RFID implementation are retailers such as Wal-Mart and the US Department of Defense. Owing to the tremendous potential benefits of RFID systems, in June 2003 Wal-Mart announced they would require their top 100 suppliers to tag all pallets and cases they shipped to Wal-Mart distribution centers by January 2005. The next top 200 suppliers were to tag all pallets and cases by January 2006 and all suppliers by the end of 2006. In January 2005, the majority of the Wal-Mart's top 100 suppliers and 37 additional suppliers complied with the mandate (O'Connor, 2005). Other early retail adopters of RFID technology include The Gap, Woolworth's, Prada, Benetton, and Marks \& Spencer (Wilding and Delgado, 2004c).

The US Department of Defense (DOD) requires its 43,000 suppliers to put RFID tags on pallets, cases and on any single item with a cost of more than $\$ 5,000$ beginning January 1,2005 
(Collins, 2004b). In addition, the US Food and Drug Administration (FDA) has called for the implementation of RFID technology to track the distribution of prescription drugs in order to protect the medical supply chain from counterfeit drugs. Companies in the health care industry will have to tag pallets and cases by 2007 to meet the FDAs' (2004) goal.

Regardless of the mandates from Wal-Mart, DOD and others, problems exist in the implementation of RFID systems. For example, many of Wal-Mart's suppliers took a low cost approach to the RFID implementation with little or no IT systems integration (O'Connor, 2005). Companies are worried about the payoff of RFID implementation due to unresolved issues such as cost, standards, tag performance, and security in the RFID implementation (Käkkäinen, 2003). Unfortunately, because of the newness of RFID little research exists to address the implementation issues systematically.

The purpose of this paper is to discuss the technical challenges and corresponding strategies of RFID implementation. This research offers useful technical guidance for companies which plan to implement RFID and we expect it to provide the motivation for much future research in this area. The paper is organized as follows. We first review the relevant literature on RFID, and discuss in detail how RFID systems work. Next, we identify the applications of RFID in various industries, followed by the technical issues of RFID implementation and the corresponding strategies available to overcome those challenges. We end the paper with concluding remarks on RFID systems and our vision for further research in this area.

\section{Radio frequency identification}

The origins of RFID technology can be traced way back to laboratory research in the $1940 \mathrm{~s}$ that focused on reflected power communication. Its commercial use began in the 1980s, primarily in railroad and trucking industries (Landt, 2001). These applications used battery powered active RFID tags and proprietary systems to track and manage capital assets, such as rail cars and cargo containers (Dinning and Schuster, 2003). The expansion of RFID into a wide variety of business applications has been due to the reduction in the cost of RFID technology through the use of non-battery powered passive tags that can replace bar codes as a means of gathering information.

Bar codes are used from the container level to the individual item level and though are currently in widespread use, they have limitations. Bar codes are the same for all items of a unique stock-keeping unit (SKU) and hence do not differentiate between items. The same bar code for all SKUs makes it difficult to track and trace items that may need to be recalled, for example, due to quality or safety concerns. In contrast, RFID can be used to identify products at the item level, can be read with no requirement for direct line of sight to the reader or scanner and can operate in harsh environments, where dirt, dust and moisture conditions can affect other types of automatic data capture systems, such as bar codes and anti-theft devices. Moreover, multiple tags can be read simultaneously and tags can also be programmed easily. Tags are capable of carrying more than 64 bits of information compared with only 19 bits in bar-code technology, thus enabling RFID to store additional information such as location, move history, destination, expiration date and environmental conditions (temperature, moisture, etc.). For a detailed comparison of RFID and bar codes, see Li and Visich (2006). In the following sections we review the literature on RFID and describe in detail how RFID systems work.

\section{RFID literature review}

It should be noted that since RFID is in its infancy, the research on RFID is fragmented and limited. We briefly review the available RFID literature. For example, Jones et al. (2004) discussed the opportunities and implementation challenges of RFID for retailers in the UK. Småros and Holmström (2000) considered RFID as a data capture method in consumers' refrigerators to develop a new type of e-grocery related service. Brewer and Sloan (1999) regarded RFID as an intelligent tracking technology in manufacturing to support logistics planning and execution. Jansen and Krabs (1999) considered RFID to control returnable containers. Käkkäinen (2003) discussed the potential of RFID implementation for increasing supply chain efficiency of short shelf life products through an RFID trial conducted at UK retailer Sainsbury's. Lapide (2004) suggested the benefits of RFID for forecasting, such as improved forecast accuracy, more accurate point of sale data from retailers, and better tracking of products sold with or without promotion. Moreover, Kärkkäinen and Holmström (2002) considered RFID as a wireless product identification technology to enable material handling efficiency, customization and information sharing in a supply chain. McFarlane and Sheffi (2003) used a ship/receive (S/R) pair structure to examine four basic logistics processes (shipping, transportation, receiving and in-facility operations) and discussed how low cost RFID can be used to improve each process. Hosaka (2004) simulated hospital bedside and nursing station conditions to automatically authenticate the matching of patients and their medical articles in order to reduce medical errors, while Janz et al. (2004) presented the technological and behavioral challenges encountered during the implementation of an RFID patient tracking system at the Elvis Presley Memorial Trauma Unit in Memphis, Tennessee.

A few studies have begun to consider the multiple participants in the supply chain and to discuss RFID applications in an integrated system. Srivastava (2004) described the benefits, current applications and impediments to implementation of RFID in supply chain management. Li and Visich (2006) reviewed the relevant literature and discussed the advantages, supply chain impacts, and the implementation challenges and the corresponding strategies of RFID in the supply chain. Visich et al. (2005) introduced RFID technology in the closed-loop supply chain and discussed how RFID is and can be utilized in the various value recovery options. Angeles (2005) provided managerial guidelines for RFID deployment in the supply chain and discussed implementation concerns.

The literature appears to have a void on the discussion of technical issues and corresponding strategies in the implementation of RFID. This paper fills the void and provides a detailed review of the technology behind RFID, the technical challenges and corresponding strategies.

\section{How RFID systems work}

All RFID systems are comprised of three main components:

1 the RFID tag, or transponder, which is located on the object to be identified and is the data carrier in the RFID system; 
2 the RFID reader, or transceiver, which may be able to both read data from and write data to a transponder; and

3 the back-end database which associates records with data collected by readers (Jones et al., 2004).

\section{RFID tags}

RFID tags can be active, passive or semi-passive. Active tags contain a battery that provides power so the tag can transmit a signal, up to $100 \mathrm{ft}$, to a reader. Passive tags do not contain a battery and hence are much cheaper than active tags. Passive tags are read when they pass through the electromagnetic field of a reader (Dinning and Schuster, 2003). A third type of tag is a semi-passive tag that is powered by both an internal battery and the electromagnetic waves sent out by the reader (Angeles, 2005). Semi-passive tags can be used to monitor environmental variables such as the temperature of frozen food or the amount of humidity in a container.

Tags can be chip-based or chipless. Chip-based tags consist of a microchip that stores data and a coupling element, such as a coiled antenna, used to communicate via radio frequency communication, while a chipless tag does not contain an integrated electronic chip. Chipless tags are used as anticounterfeiting and anti-theft devices. There are three types of chip-based tags:

1 read-only;

2 write once/read many times; and

3 read-write.

Data on read only-tags cannot be changed unless the chip is electronically reprogrammed and they are often used to track assets that will have a unique ID over their lifetime. A readwrite tag will allow changes to the stored data and they are used to track items through the supply chain (Wilding and Delgado, 2004a). We will focus on the passive, chip-based, read-write tags for the following reasons:

- passive tags are significantly cheaper than active tags and therefore are used to cost effectively track at the pallet, case and item levels;

- practitioner interest in applications of RFID technology to date is primarily in passive tags; and

- read-write tags provide a living history of the item being tracked and therefore increase the transparency in the supply chain.

RFID tags can be manufactured from a variety of chip and code formats. One code format that enjoys substantial support in the retail industry is the electronic product code (EPC). The EPC uses a 96 bit scheme advocated by EPCglobal (previously known as the Auto-ID Center). The 96 bits on a tag are allocated as follows:

- 8 bits in the header to identify the EPC version number;

- 28 bits to identify the manufacturer (the EPC Manager);

- 24 bits to identify the SKU (the object class); and

- 36 bits to identify the unique product item (the serial number).

The 96 bits EPC format can identify over 268 million manufacturers, more than 16 million SKUs for each manufacturer and in turn nearly 69 billion items in each SKU (Brock, 2001). EPC global has developed a standard for the $13.56 \mathrm{MHz}$ frequency (Class 1) and for the ultra high frequency (UHF) (2 standards: Classes 0 and 1). In December 2004 EPCglobal introduced a new standard (Generation 2) to replace Classes 0 and 1 . Generation 2 protocols will allow tags to contain more data and ease the ability to program tags (Sullivan, 2004b).

\section{How RFID systems work}

Figure 1 shows how an RFID system works. First, a unique identifier, such as an electronic product code (EPC), is embedded into the microchip in a tag. The microchip can also incorporate functionality beyond simple identification and include integrated sensors, read/write storage, encryption and access control. The tag is then attached to an item, case or pallet. As the item/case/pallet moves into the scanning range of the reader, the reader sends out electromagnetic waves that form a magnetic field when they "couple" with antenna on the RFID tag. The tag draws power from the magnetic field and uses it to power the microchips' circuits. The microchip then modulates the signal received in accordance with its identification or programmed code and transmits or reflects a radio frequency signal. The modulation is in turn picked up by the reader, which decodes the information contained in the transponder and depending upon the reader configuration, either stores the information, acts upon it, or transmits the information to the host computer via the communications port (Jones et al., 2004).

The Auto-ID center at MIT is creating an infrastructure, consisting of EPC, Object Naming Service (ONS), physical makeup language (PML) and data handling middleware (called Savant), to support wide adoption of RFID technology in various industries. For example, when the reader picks up a signal, Savant uses the EPC on the tag to contact the ONS. The ONS can be on a local network or on the internet, and it is similar to the domain name service that associates an internet provider address with a domain name. The ONS serves as a directory that locates the server containing the information for the item being scanned. That information is collected by Savant, and then communicated to the databases and supply chain applications requiring the information. The communication format for the data is physical markup language (PML). PML is based on the extensible markup language (XML - popular in e-commerce transactions) and it has the ability to describe physical objects, processes and environments in a standardized way (Angeles, 2005; Dinning and Schuster, 2003).

\section{RFID applications}

In order to be more competitive and efficient, a wide variety of businesses and organizations have or are planning to implement RFID systems. This section discusses the application of RFID technology in retailers and manufacturers, which are currently the major adopters of RFID technology. The applications of RFID in health care and other fields are also discussed.

\section{Retailers}

Wal-Mart has implemented an in-store RFID tracking system in order to reduce stockouts by installing readers at the receiving docks at the back of the building, next to trash compactors, and between the back and the retail floor. Incoming cases are read at the loading dock before they are stored in the backroom and when they are moved to the retail floor. Point of sale data are used to determine shelf inventory by subtracting cases sold from cases brought out of the back room and the system automatically generates a pick list for items that will soon be depleted. Wal-Mart employees use 
Figure 1 A RFID system

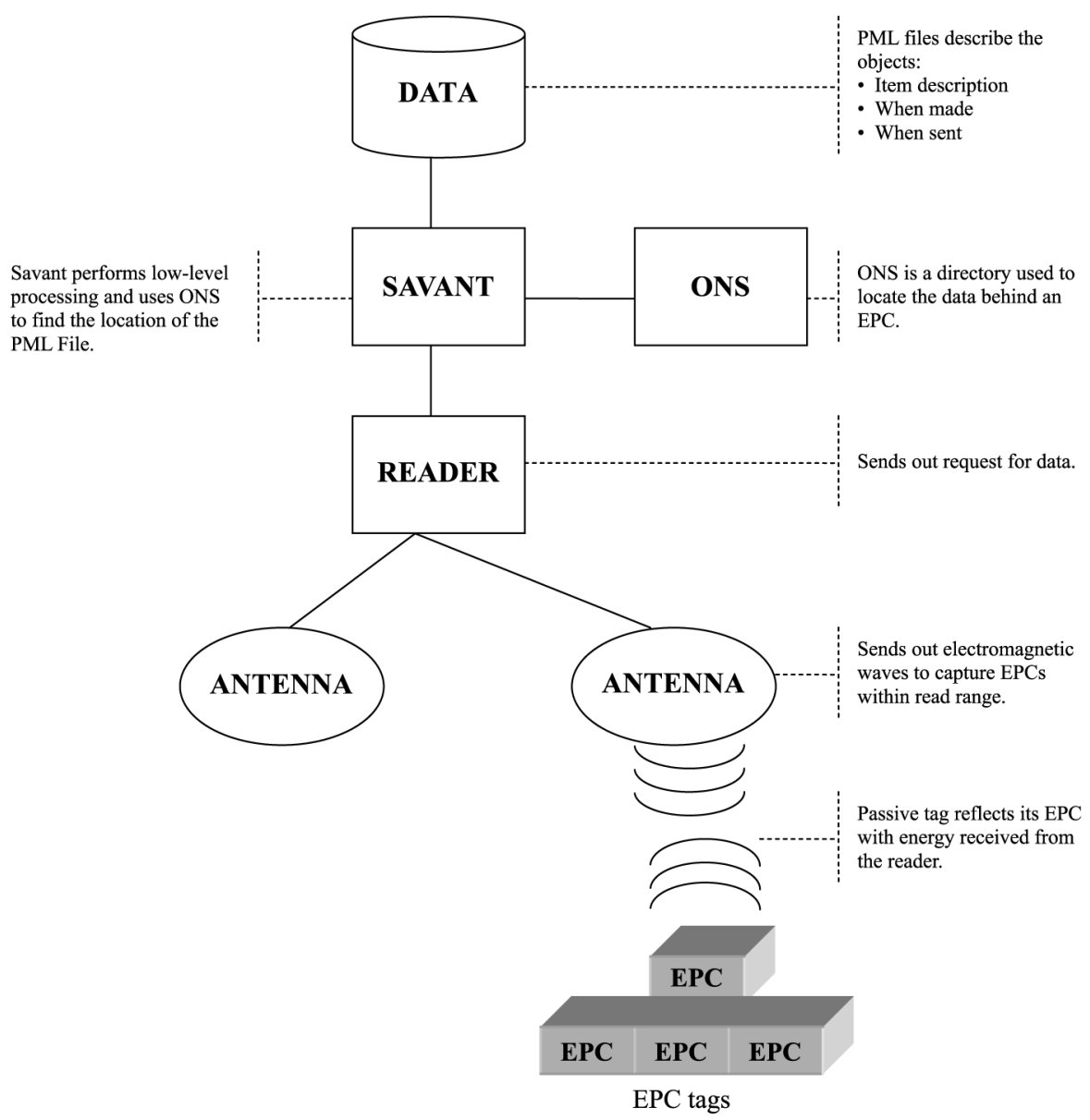

Source: (Adopted from Dinning and Schuster, 2003)

a handheld RFID reader that beeps when he or she is close to the needed item, which speeds up the stocking process. Empty cartons are scanned before being discarded in the trash compactor and the inventory status is changed to "on shelf". Information from all three read points is shared with suppliers (Roberti, 2005).

The food division of London-based retailer Marks \& Spencer (M\&S) replaced bar codes with RFID tags to track 3.5 million reusable plastic trays stacked in plastic dollies. Their annual throughput of plastic trays is approximately 85 million and 70 percent of the product line is perishable. The reported benefits include an 83 percent reduction in read time for each tagged dolly, a 15 percent reduction in shrinkage, a reduction in lead time, and improved product management due to near real time tracking (Wilding and Delgado, 2004b).

\section{Manufacturers}

Custom motorcycle manufacturer Viper Motorcycle uses RFID tags in the production process to track subassemblies as they move through the facility in order to determine where motorcycles are in the production process (Sullivan, 2004a). Shrinkage and theft can also be reduced through RFID tag use. For instance, Viper Motorcycle installed RFID tags on all parts that have $\$ 75$ or greater value. After conducting a random inventory audit, management located a missing $\$ 2,400$ transmission in an employees van (Sullivan, 2004a).
Scottish Courage, one of the largest brewers in the UK, tagged 1.9 million kegs with low frequency, read/write tags. Some of their reported benefits were a reduction in keg losses from 4 to 2 percent, the identification and elimination of "unofficial supply chains" and a reduction in distribution overheads due to fewer distribution errors (Wilding and Delgado, 2004b).

\section{Health care/pharmaceutical industry}

Though widespread adoption and implementation of RFID technology has not yet occurred in healthcare, a few leaders have emerged. St Luke's Health System, in Kansas City, Missouri, is considering implementing bedside RFID technology in its new hospital opening in January 2006 (Becker, 2004). Even though St Luke's is currently using barcodes and found bar-coding reduced medical errors, the company identified some problems associated with barcoding: moisture from hand washing can degrade bar codes; and bar codes are unsuitable for tracking ambulatory patients. Cardinal Health Inc., the leading supplier of products and services supporting the healthcare industry, is placing RFID tags on surgical medical products to ensure that no items are "left inside the patient during surgery" (McGee, 2004).

In November 2004, USA pharmaceutical company Purdue Pharma began applying read-only tags to every 100-tablet bottle of OxyContin to be shipped to Wal-Mart and drug 
wholesaler HD Smith. The tagging is part of the company's efforts to meet Wal-Mart's RFID mandate and to combat the growing market for counterfeit and stolen drugs in the USA (Collins, 2004c).

\section{Other applications}

RFID tags have been utilized in a wide variety of other applications from tagging humans and animals, to uniforms and luggage. Denmark's Legoland amusement park offers parents the option of using wireless-enabled RFID tagged wristbands to keep track of their children. The wristbands can track a lost child to within $5 \mathrm{ft}$ of their location (Swartz, 2004). The tracking of livestock has been one of the most successful applications of RFID. Over 40 million animals around the world are implanted with RFID tags (Stackpole, 2003). The Star City Casino in Sydney, Australia sews RFID tags into all garments as a way to control the 80,000 outfits worn by employees. The washable tags have all but eliminated lost garments and laundry bill discrepancies (Ferguson, 2002). Delta Airlines plans to deploy disposable tags to locate lost luggage, which costs the company US $\$ 100$ million annually (Swartz, 2004).

\section{Technical challenges and strategies}

Many problems exist in the application of RFID technology. An online survey of more than 350 IT executives in April 2004 revealed that the top three business risks of using RFID are that:

1 technical standards are not final;

2 business benefits or return on investment are unclear; and 3 there is a lack of industry-wide adoption (Emery, 2004).

This is further substantiated by a survey conducted by the IOMA (2004). According to this report the hurdles to RFID adoption are a lack of global standards, multiple frequencies and specifications for tags, reader compatibility with supply chain partners, and security issues. A survey of 50 companies conducted by ABI Research in the third quarter of 2004 found that return on investment (ROI) uncertainty was the most commonly cited impediment to widespread deployment of RFID followed by uncertainty over technology standards, tag/ transponder costs, and technology flux (Collins, 2004d). It is clear from the above that there are many issues that need to be resolved before widespread RFID deployment can occur. We now discuss the major RFID implementation challenges and the corresponding strategies from a technical aspect (Table I).

\section{RFID cost}

Cost or ROI is a major issue in the implementation of RFID technology. RFID systems require expenditures for tags, readers, hardware, software and system maintenance (Logistics and Transport Focus, 2004). Other tag costs include attachment of the tag to the pallet/case/item to be tracked and programming. In addition, companies will need to run existing bar code systems and RFID tags simultaneously in order to meet the requirements of various customers who are not implementing RFID systems.

The consulting firm A.T. Kearney estimates that major retailers will have to invest approximately $\$ 400,000$ at each distribution center, $\$ 100,000$ at each store to read and manage the data, and $\$ 35-40$ million to integrate the RFID system into existing information systems (Feder, 2003). However, the cost of passive tags has fallen from about $\$ 1$ per
Volume $26 \cdot$ Number $3 \cdot 2006 \cdot 193-202$

tag in 2000 (Jones et al., 2004) to about 20 cents for the cheapest tags in late 2004 (Feder, 2004). And, the cost of readers and allied equipment has also fallen significantly (Jones et al., 2004).

Dinning and Schuster (2004) provide an RFID scorecard and payback table that Dell Computer uses to make RFID investment decisions. The scorecard is used to identify highpotential RFID projects that become candidates for more detailed financial analysis using the payback table. The payback table considers benefits, one-time costs, and recurring costs. According to Roberti (2004a), companies should not wait for the price of tags to drop to 5 cents before deploying an RFID system. Companies need to explore opportunities in using RFID now so they can develop a business case for deploying RFID, correct mistakes in current processes, educate and train workers, and phase in the technology.

\section{RFID standards}

To gain the maximum benefits from RFID in the supply chain, various business partners worldwide need to use common tags, readers and frequencies so that they can be used beyond the confines of one company's walls. Kay (2003) points out that the lack of uniformity in RFID technology and standards keep the costs high, and that standards are the key to the proliferation of RFID technology. The establishment of a standard will force the cost to drop since RFID product suppliers can all produce compatible chips, readers, associated hardware and software.

Within the RFID market, a number of standards have been developed. For example, several ISO standards are now established, including ISO 11785 for $125 \mathrm{KHz}$ (low frequency), ISO 15693 for $13.56 \mathrm{MHz}$ (mid frequency), and ISO $18000-6$ for $860-930 \mathrm{MHz}$ (UHF) (RFID fournal, 2003). The American National Standards Institute has adopted the $915 \mathrm{MHz}$ UHF frequency as the standard frequency for passive RFID systems (Porter et al., 2004). Since, Wal-Mart has selected the UHF frequency for its RFID systems (Weil, 2004), UHF is considered the standard frequency for the retail industry supply chain.

\section{Tag and reader selection}

The performance of the tags and readers can be influenced by many factors such as tag frequency, reader antenna shape, and tag antenna design. For example, low frequency tags require a larger antenna which increases the tag size and cost. High frequency tags can be smaller and cheaper, but require a more expensive reader. Reader range and speed of data transfer increase as frequency increases, but so does the health risk to workers due to radiation. Higher frequencies also have reflection problems and are negatively impacted by metal, liquid, glass and moist environments. Low frequencies are not impacted by the presence of metal and can even read through some non-ferrous metals (Wilding and Delgado, 2004a). Reader antenna shape and tag antenna design also affect RFID system performance. A circular polarized reader antenna should be used if the tag orientation within the radio frequency field is unknown, while a linear polarized reader antenna provides greater radio frequency penetration and longer read ranges. On a passive tag, the most important design characteristic is the antenna. A multi-directional antenna is less orientation specific and performs better than a single-directional antenna (since it reduces human intervention to orient the tag), but at a higher cost (Weil, 2004). 

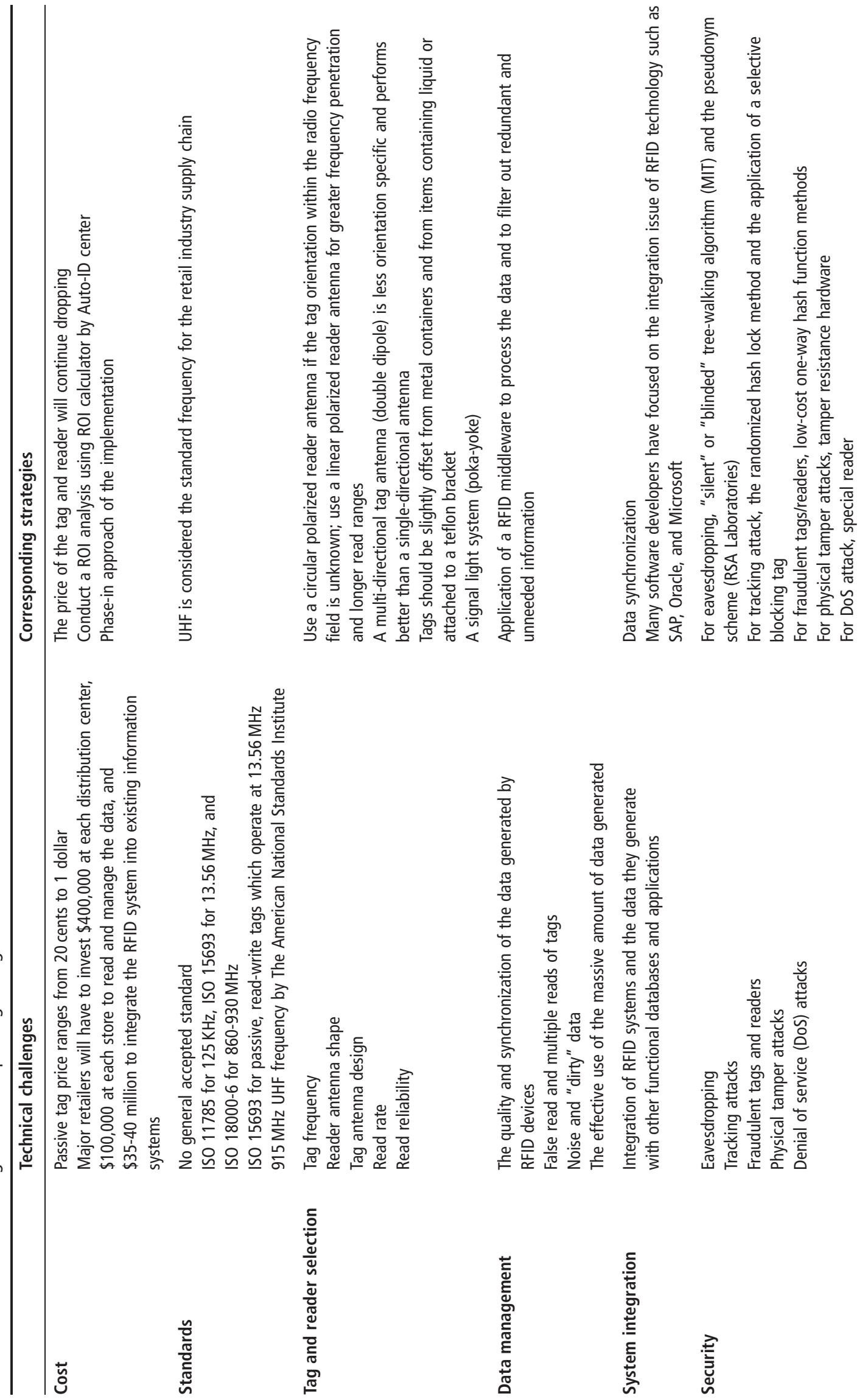

ฝับ 
Other performance factors include tag separation (the minimum distance between tags) and the number of tags that could be read simultaneously within the transmitting antenna capture zone without a negative impact on system performance (Porter et al., 2004).

A key performance factor of an RFID system is the read rate. Wal-Mart has mandated that tags be read 100 percent of the time as pallets move through loading dock doors and as cases move at up to $540 \mathrm{ft}$ per minute on conveyors (Roberti, 2004b). Wal-Mart suppliers testing the RFID system have had mixed results. Kimberly-Clark (producer and supplier of paper-based products which are RFID friendly) has achieved read rates ranging from 85 to 94 percent for cases on a pallet, while Unilever (makers of shampoo and other personal hygiene products) has reported low readability rates for cases stacked on pallets and less than 100 percent readability for cases moving on a conveyor (Roberti, 2004b).

Some methods to improve read rates are:

- use a double dipole antenna (two antennas at a $90^{\circ}$ offset) which allow the tags to be read regardless of their orientation to the reader (Collins, 2003);

- offset tags from metal containers or items containing liquids (Porter et al., 2004);

- attach the tag to a Teflon bracket that is then attached to a metal object (Johnson, 2002); and

- use conductive ink to print the tag antenna directly onto cardboard packaging (Dinning and Schuster, 2003).

Associated with tag performance is tag reliability. A defective label cannot be read and therefore a system must be in place to signal if a tag is not read. Poka-yoke systems can be designed to ensure a tag has been read. Pacific Cycle uses a signal light located on the reader that illuminates when a tag has been successfully read (Swedberg, 2004). A signal light system can also be used for multiple item reads to reconcile information on a pallet tag with the number of cases read on the pallet. For example, if the pallet tag transmits ten cases to the reader and only nine case tags are read, then a light could indicate a shortage.

\section{Data management}

Venture Development Corp. surveyed 100 Chief Technology Officers and found that data management and monitoring has been rated as one of most important issues in the implementation of RFID systems (O'Connor, 2004). More than half of the surveyed individuals expressed concern with the quality and synchronization of the data generated by RFID devices. The respondents indicated the problems with RFID devices sending false reads or multiple reads of the same tag. The finding is supported by the study of Jones et al. (2004), who found that a significant amount of noise and "dirty data" are generated from an RFID-based system. The key to data management is the application of middleware to process the data, to filter out redundant and unneeded information, and to ensure accuracy of data and item validity.

Another data management issue is related to the effective use of the massive amount of data captured by RFID systems throughout the supply chain. A field research conducted by Wal-Mart, the Auto-ID Center and key suppliers at WalMarts' pilot distribution center in Oklahoma for tagging of cases resulted in the generation of 30 times more data as products were tracked through the supply chain (Wilding and Delgado, 2004c).

\section{System integration}

A survey of 275 respondents working in the packaging industry by Cap Gemini Ernst and Young LLC revealed that 46 percent of the respondents consider integration as the single biggest concern with RFID systems (Ferguson, 2004). The challenge of RFID implementation comes from integrating RFID systems and the data they generate with other functional databases and applications (Jones et al., 2004). A key necessary first step in system integration is data synchronization. All items being tagged need to be named consistently throughout the supply chain. This will eliminate data redundancy (the same data being entered multiple times under different names), and facilitate internal and external communication (Moore, 2004). Also, many software developers have focused on the integration issue of RFID technology. Major ERP providers SAP (RFID fournal, 2004) and Oracle (Westervelt, 2004) currently offer applications that capture, manage and analyze data from RFID readers. Microsoft plans to enter the RFID market in the first half of 2005 by coding RFID specifications into the warehouse management module of the Axapta ERP suite (Foley and Sullivan, 2004).

\section{Security}

Regardless of its potential benefits, unprotected passive RFID tags face a variety of malicious attacks including eavesdropping and tampering (spoofing), unauthorized tracking, fraudulent tags and readers, and denial of service (Weis et al., 2003). Data obtained from RFID tags can be misused or revealed illegally. Hackers could reduce the price of expensive items and use self-checkout to avoid store clerks (Lemos, 2004). Retail inventory labels with unprotected tags could be monitored and tracked by competitors and sales data may be gleaned by correcting changes over time (Weis et al., 2003).

Efforts have been made to improve the security of the passive RFID tags. Currently, tag information can be easily eavesdropped because it is explicitly repeated by the reader using a "loud" tree-walking algorithm over the high-power forward channel (reader-to-tag) in order to select a single tag to read at a time (called singulation procedure). Two different methods have been proposed for securing passive RFID tags from eavesdropping and tampering. The first is called "silent" or "blinded" tree-walking algorithm and it has been proposed by the MIT Auto-ID Laboratory (Weis et al., 2003). The readers use the tree-walking algorithm to obtain common bits of information from RFID chips on the backward channel but do not repeat them (i.e. keep "silent") on the forward channel to prevent eavesdropping. The silent tree-walking algorithm does not add any overhead to the tag reading. The second method is a pseudonym scheme that has been proposed by the RSA Laboratories (Juels, 2004). In this scheme, an RFID tag stores a short list of random identifiers or pseudonyms that are linked to the authorized verifiers and known to the verifier to be equivalent. Each time the tag is queried, it emits the next pseudonym in the list, cycling to the beginning identifier when the list is exhausted. Therefore, the real identity of the RFID tag is hidden. The pseudonym method requires storage of the pseudonym list on the tag and it has the advantage of securing eavesdropping on both the forward and the backward channel.

Methods have also been proposed to handle tracking attacks. For example, Ranasinghe et al. (2004) proposed that 
tags be disabled at the consumer's request. Weis et al. (2003) proposed the randomized hash lock method. In this method, tags can be locked by a single instruction from the reader. In order to unlock the randomized "hash lock" the reader needs to traverse through all the possible tag values in its expected reading domain in a "brute force" style. The disadvantage of this method is that it will reduce the efficiency of the reader and therefore cannot be used in an environment where a high read rate is required or a large number of tags must be read simultaneously. This loss of efficiency may be unacceptable for supply chain management systems. Juels et al. (2003) proposed the application of a selective blocking tag which prevents an unauthorized reader from interrogating a tag in the consumer's range of privacy. Although the authors only propose blocker tags as a method of consumer privacy protection, the application of a large number of blocker tags can possibly protect a larger space and can therefore be used to shield products and pallets in transportation against corporate espionage.

To prevent against fraudulent tags and readers, mutual authentication must be performed. The traditional encryption/authentication technologies such as advanced encryption standard (AES) and RSA (the RSA encryption algorithm is named after its three creators: Ron Rivest, Adi Shamir, and Leonard Adleman) cannot be implemented for low-cost RFID tags because of the limited number of logical gates. Several low-cost one-way hash function methods are proposed for RFID authentications (Ranasinghe et al., 2004; Weis et al., 2003). Some authentication methods are based on mathematical functions that are simple enough to be implemented on RFID and can be used repetitively to increase the difficulty of code cracking (Molnar and Wagner, 2004; Vajda and Buttyán, 2003). The security of low-cost RFID tags should not be measured to be "sufficient" using these authentication technologies compared to a larger computing system applying traditional encryption. However, these methods successfully set a lower bound on cost to impersonate a low-cost RFID tag or reader and make it impossible to crack the encryption unless the hacker has plenty of time and sophisticated computing devices.

Denial of service attacks may be carried out by a fraudulent radio frequency source, an illegitimate blocker tag, or a large number of fraudulent tags (Juels et al., 2003; Molnar and Wagner, 2004; Weis et al., 2003). These types of attacks can be handled through the use of special readers that can immediately identify the attack (Juels et al., 2003).

\section{Conclusion}

In this paper we have described the technical aspects and tradeoffs of RFID systems, presented case studies of RFID applications in a variety of contexts, and discussed the technical challenges of the implementation and corresponding strategies. As RFID system cost decreases and standards become clearer it is predicted that the tags will gain widespread acceptance in all types of industries.

Successful implementation of an RFID system will require a long-term strategic plan, careful planning at the tactical level to roll out deployment throughout the organization, and a change in operational business processes. And, since RFID will cut across organizational business functions, crossfunctional teams will also be needed as well. Suppliers and manufacturers should look at the mandates from retailers and government agencies as a business opportunity to improve the visibility, security and efficiency of their own business processes and of partners in their supply chain. It is well understood that the biggest benefits of RFID implementation come from solutions across the supply chain. Moreover, successful RFID implementation will require a change in culture, process, and technology within and across organizations.

Owing to the infancy of RFID, research is needed to facilitate the effective implementation of RFID technology for a wide variety of business applications. The appropriate selection and location of readers and tags for use in various operating conditions needs to be determined. Efficient security methods need to be developed that can simultaneously protect readers and tags from a variety of malicious attacks. We need to identify best practices and applications for data management and the integration of RFID systems with both internal operating systems and supply chain partners. Finally, new data analysis and decision making tools will need to be created in order to gain competitive advantages from the large volume of near realtime data generated by RFID systems.

\section{References}

Angeles, R. (2005), "RFID technologies: supply-chain applications and implementation issues", Information Systems Management, Vol. 22 No. 1, pp. 51-65.

Becker, C. (2004), "A new game of leapfrog?", Modern Healthcare, Vol. 34 No. 28, p. 38.

Brewer, A. and Sloan, N. (1999), "Intelligent tracking in manufacturing", Fournal of Intelligent Manufacturing, Vol. 10, pp. $245-50$.

Brock, D.L. (2001), "The electronic product code (EPC): a naming scheme for physical objects”, MIT Auto-ID Center White Paper, January 1, pp. 1-21.

Collins, J. (2003), "RFID speeds sorting of packages", RFID fournal, August 6, available at: www.rfidjournal.com/article/ articleprint $/ 526 /-1 / 1 /$ (accessed July 13, 2004)

Collins, J. (2004a), "RFID brings order to the law", RFID Fournal, July 7, available at: www.rfidjournal.com/article/ articleview/977/1/4/ (accessed March 18, 2005)

Collins, J. (2004b), "DOD updates RFID policy", RFID Fournal, April 1, available at: www.rfidjournal.com/article/ articleprint/856/-1/1/ (accessed July 13, 2004)

Collins, J. (2004c), "Purdue pharma tags OxyContin", RFID fournal, November 16, available at: www.rfidjournal.com/ article/articleprint/1241/-1/1/ (accessed December 3, 2004)

Collins, J. (2004d), "RFID's ROI tops user concern", RFID Fournal, October 26, available at: www.rfidjournal.com/ article/articleprint/1207/-1/1/ (accessed December 3, 2004)

Dinning, M. and Schuster, E. (2003), "Fighting friction", APICS - The Performance Advantage, February, pp. 26-31.

Dinning, M. and Schuster, E. (2004), "Getting on board: building a business case for auto-ID at Dell", APICS - The Performance Advantage, October, pp. 34-7.

Emery, G.R. (2004), "IT execs prepare for an RFID revolution", Washington Technology, June 29, available at: www.washingtontechnology.com/news/1_1/industry/ 23875-1.html (accessed August 12, 2004)

FDA (2004), Combating Counterfeit Drugs: A Report of the Food and Drug Administration, US Department of Health and 
Human Services, Food and Drug Administration, Rockville, MD.

Feder, B.J. (2003), "Wal-Mart plan could cost suppliers millions", www.nytimes.com, November 10, available at: wwwnytimes.com/2003/11/10/technology/10radio.html (accessed August 29, 2004)

Feder, B.J. (2004), "Keeping better track from factory to checkout", The New York Times, November 11, p. E5.

Ferguson, G.T. (2002), "Have your objects call my objects", Harvard Business Review, Vol. 80 No. 6, pp. 138-44.

Ferguson, R.B. (2004), "Taking on RFID challenge", Eweek, April 5, p. 12.

Foley, J. and Sullivan, L. (2004), "Cheap, easy RFID?", Information Week, July 19, pp. 22-4.

Hosaka, R. (2004), "Feasibility study of convenient automatic identification system of medical articles using LF-band RFID in hospital", Systems and Computers in Fapan, Vol. 35 No. 10, pp. 571-8.

IOMA (2004), "RFID pilots roll out but 'wait-and-see' attitude still prevails", Inventory Management Report, pp. 4-6, The Institute of Management and Administration, July, available at: www.ioma.com (accessed August 12, 2004)

Jansen, R. and Krabs, A. (1999), "Automatic identification in packing - radio frequency identification in multi-way system", Packing Technology and Science, Vol. 12, pp. 229-34.

Janz, B.D., Pitts, M.G. and Otondo, R.F. (2004) paper presented at Workshop, the 35th Annual Meeting of the Decision Sciences Institute, Back to future with RFID, lessons learned-some old, some newBoston, MA, November 20-23.

Johnson, D. (2002), "RFID tags improve tracking, quality on Ford line in Mexico", Control Engineering, Vol. 49 No. 11, p. 16.

Jones, P., Clarke-Hill, C., Shears, P., Comfort, D. and Hillier, D. (2004), "Radio frequency identification in the UK: opportunities and challenges", International fournal of Retail E Distribution Management, Vol. 32 No. 3, pp. 164-71.

Juels, A. (2004), "Minimalist cryptography for RFID tags", in Blundo, C. and Cimato, S. (Eds), Security in Communication Networks, Springer, New York, NY, pp. 149-64.

Juels, A., Rivest, R. and Szydlo, M. (2003), "The blocker tag: selective blocking of RFID tags for consumer privacy", in Atluri, V. (Ed.) paper presented at 10th ACM Conference on Computer and Communications Security, Washington, DC, USA, October, pp. 103-11.

Käkkäinen, M. (2003), "Increasing efficiency in the supply chain for short shelf life goods using RFID tagging", International fournal of Retail \& Distribution Management, Vol. 31 No. 10, pp. 529-36.

Kärkkäinen, M. and Holmström, J. (2002), "Wireless product identification: enabler for handling efficiency, customization and information sharing", Supply Chain Management: An International fournal, Vol. 7 No. 4, pp. 242-52.

Kay, E. (2003), "What's the next step for RFID", Frontline Solutions, March, pp. 21-5.

Landt, J. (2001), Shrouds of Time: The History of RFID, AIM Publications, Pittsburgh, PA.

Lapide, L. (2004), "RFID: what's in it for the forecaster?", The fournal of Business Forecasting, Vol. 23 No. 2, pp. 16-19.

Lemos, R. (2004), "RFID tags become hacker target", CNET News.com, July 28, available at: http://news.com.com/ 2100-1029-5287912.html (accessed August 29, 2004)
Li, S. and Visich, J.K. (2006), "Radio frequency identification: supply chain impact and implementation challenges", International fournal of Integrated Supply Management, Vol. 2 No. 4, pp. 407-24.

Logistics and Transport Focus (2004), "Business in the dark about RFID", Logistics and Transport Focus, April, p. 14.

McFarlane, D. and Sheffi, Y. (2003), "The impact of automatic identification on supply chain operations", The International Fournal of Logistics Management, Vol. 14 No. 1, pp. 1-17.

McGee, M. (2004), "Health-care I.T. has a new face", InformationWeek, May 10, p. 16.

Molnar, D. and Wagner, D. (2004), "Privacy and security in library RFID: issues, practices, and architectures", paper presented at ACM Conference on Computer and Communications Security.

Moore, B. (2004), "AIDC in the warehouse: hardware's easy; software's hard", Material Handling Management, Vol. 59 No. 8, pp. 25-31.

O'Connor, M.C. (2004), "RFID users want clear data", RFID fournal, November 30, available at: www.rfidjournal. com/article/articleview/1232/1/1/ (accessed March 22, 2005)

O’Connor, M.C. (2005), "Suppliers meet mandate frugally", RFID fournal, January 3, available at: www.rfidjournal.com/ article/articleview/1308/1/1/ (accessed March 22, 2005)

Porter, J.D., Billo, R.E. and Mickle, M.H. (2004), “A standard test protocol for evaluation of radio frequency identification systems for supply chain applications", Fournal of Manufacturing Systems, Vol. 23 No. 1, pp. 46-55.

Ranasinghe, D.C., Engels, D.W. and Cole, P.H. (2004), "Low-cost RFID systems: confronting security and privacy", Proceedings of MIT Auto-ID Labs Research Workshop, available at: www.epfl.ch/ gavoine/rfid/">http:// lasecwww.epfl.ch/ gavoine/rfid/ (accessed March 23, 2005)

RFID fournal (2003), "ISO moves on RFID standards", RFID fournal, February 7, available at: www.rfidjournal. com/article/articleprint/992/-1/1/ (accessed January 30, 2005)

RFID fournal (2004), "SAP launches RFID package", RFID Fournal, January 15, available at: www.rfidjournal.com/ article/articleprint/737/-1/1/ (accessed August 16, 2004)

Roberti, M. (2004a), "Tag cost and ROI", RFID fournal, February 16, available at: www.rfidjournal.com/article/ articleview/796/1/2/ (accessed March 22, 2005)

Roberti, M. (2004b), "Wal-Mart suppliers discuss RFID", RFID fournal, May 24, available at: www.rfidjournal.com/ article/articleprint/956/-1/1/ (accessed July 13, 2004)

Roberti, M. (2005), "Wal-Mart begins RFID process change", RFID fournal, February 1, available at: www. rfidjournal.com/article/articleprint/1385/-1/1/ (accessed February 23, 2005)

Småros, J. and Holmström, J. (2000), "Viewpoint: reaching the consumer through e-grocery VMI", International Fournal of Retail \& Distribution Management, Vol. 28 No. 2, pp. 55-61.

Srivastava, B. (2004), "Radio frequency ID technology: the next revolution in SCM", Business Horizons, Vol. 47 No. 6, pp. 60-8.

Stackpole, B. (2003), "RFID finds its place", Electronic Business, Vol. 29 No. 9, pp. 42-6. 
Sullivan, L. (2004a), "RFID cruises down the highway", Information Week, July 12, p. 47.

Sullivan, L. (2004b), "Update: next generation RFID standard is approved", Information Week, December 17, available at: www.informationweek.com/showArticle.jhtml? articleID $=55800518^{\prime}$ (accessed January 30, 2005).

Swartz, N. (2004), "Tagging toothpaste and toddlers", Information Management fournal, Vol. 38 No. 5, p. 22.

Swedberg, C. (2004), "Bike maker rolls out RFID", RFID Fournal, June 25, available at: www.rfidjournal.com/article/ articleprint/999/-1/1/ (accessed July 13, 2004)

Vajda, I. and Buttyán, L. (2003), "Lightweight authentication protocols for low-cost RFID tags", paper presented at 2nd Workshop on Security in Ubiquitous Computing, in conjunction with Ubicomp 2003, Seattle, WA, USA, October 12.

Visich, J.K., Li, S. and Khumawala, B.M. (2005), "A framework for the implementation of radio frequency identification technology in closed-loop supply chains: impact and challenges", ERP Teaching $\mathcal{E}$ Research, pp. 7-34, (Innovation Monograph I, November 2005) Kelley ERP Center and SAP University Alliance Program.
Weil, M. (2004), "RFID confusion and possibility", APICS the Performance Advantage, February, pp. 50-4.

Weis, S., Sarma, S., Rivest, R. and Engels, D. (2003), "Security and privacy aspects of low-cost radio frequency identification systems", in Hutter, D., Müller, G., Stephan, W. and Ullmann, M. (Eds) paper presented at First International Conference on Security in Pervasive Computing, SPC 2003, Vol. 2802 of LNCS, pp. 454-69.

Westervelt, R. (2004), "Oracle sensors RFID data", SearchOracle.com, available at: http://searchoracle. techtarget.com/originalContent/ 0,289142,sid41_gci957327,00.html (accessed August 16, 2004)

Wilding, R. and Delgado, T. (2004a), "The story so far: RFID demystified", Logistics and Transport Focus, April, pp. 26-31.

Wilding, R. and Delgado, T. (2004b), "RFID demystified: supply-chain applications", Logistics and Transport Focus, April, pp. 42-8.

Wilding, R. and Delgado, T. (2004c), "RFID demystified: company case studies", Logistics and Transport Focus, June, pp. 32-42.

To purchase reprints of this article please e-mail: reprints@emeraldinsight.com Or visit our web site for further details: www.emeraldinsight.com/reprints 